Collaboration within Engineering Education Research's Community of Practice

Scottie-Beth Fleming, Georgia Institute of Technology

Scottie-Beth Fleming is an Aerospace Engineering PhD student and NSF GRFP Fellow in the Cognitive Engineering Center (CEC) at Georgia Tech. She graduated with honors from Georgia Tech in 2009 with a B.S. in Aerospace Engineering and in 2013 with an M.S. in Aerospace Engineering. Her research within the CEC examines training approaches for pilots, interdisciplinary teams within the engineering design process, and human interaction with technology. 


\title{
Collaboration within Engineering Education Research's Community of Practice
}

\begin{abstract}
Engineering education research (EER) is a relatively young field of inquiry, established with the intent to improve the academic experiences of young and emerging engineers. While many researchers' perceptions of how to improve engineering education stem from traditional classroom experiences, a select group of researchers belong to EER-oriented departments, labs, and research centers. These on-campus resources create a formal bridge between EER-expert networks and offer researchers an opportunity to collaborate with other like-minded individuals. However, researchers lacking access to similar EER resources may be unable to establish connections to engineering education's expert community of practice.

The purpose of this paper is to answer the question "How is collaboration within the EER community of practice impacted by an individual's access to EER resources?" Formal collaborations were catalogued using co-authorship data from publications in the Journal of Engineering Education between the years 2008 to 2012. Influential researchers, collaboration trends, critical brokers, and other hidden structures were analyzed using social network analysis methods. Results of this study found that researchers on campuses lacking formal EER resources are unable to broker connections into EER's expert community of practice. Consequently, these researchers may be unable to adopt best practices from and exchange relevant information with the greater community.
\end{abstract}




\section{Introduction}

Research collaboration often occurs between colleagues working within similar as well as different disciplines. Collaboration is known to boost creativity, increase access to relevant skills and knowledge, provide intellectual companionship, and grow researcher network size. ${ }^{1-3}$ Through collaborations, social capital is leveraged as a transfer of information and knowledge is facilitated through formal and informal networks. ${ }^{4}$ Additionally, future opportunities for collaboration and/or funding are enhanced by growing and strengthening collaborator networks.

Interdisciplinary collaborations give a deeper understanding to complex problems, increase overall research impact, and enable a diverse approach to solving problems and generating new knowledge. ${ }^{5}$ However, often research collaboration will take place between individuals within similar networks (such as department, institute, or discipline networks), because researchers from comparable backgrounds are able to relate easily to one another's perspectives. Homophilious partnerships limit researcher interaction with diverse networks and may impede access to relevant knowledge and subsequently inhibit creative thinking. ${ }^{6}$

Interdisciplinary and multidisciplinary collaboration are common themes to research partnerships within engineering education research (EER). Many engineering education researchers are housed in their primary engineering discipline's academic department (e.g. systems engineering, mechanical engineering, or aerospace engineering) and do not share a common interest in EER with their nearby colleagues. This type of multidisciplinary distribution of expertise likely enables and encourages collaboration between engineering education researchers from a variety of backgrounds. ${ }^{7}$

While many of these researchers' perceptions of how to improve engineering education stem from traditional classroom experiences, a select group of researchers belong to departments, labs, and centers primarily devoted to studying EER.$^{8-10}$ These programs are increasingly graduating masters and doctoral students with a specific focus in EER. While engineering education departments offer researchers a new opportunity to collaborate with other like-minded individuals, they may also limit researcher motivation to interact outside their known network. ${ }^{4}$ Moreover, researchers on campuses lacking formal EER resources may not have access to these "expert" networks due to a deficiency of brokers between communities. ${ }^{11}$

Burt (2004) discusses the roles of brokers in connecting people across groups. In the absence of brokerage, homophily restricts the exchange of novel information and attitudes among a sociodemographically diverse population. ${ }^{6}$ Further, unconnected groups are unable to observe the best practices of well-connected expert groups. ${ }^{11}$ Brokerage is important to sharing knowledge, synthesizing ideas, and exchanging beliefs between distinct groups.

Previous studies within EER have examined collaboration, with many of these publications focusing on the benefits of academic collaboration, strategies for finding collaborators, and reasons for collaboration. ${ }^{7,12-14}$ One study in particular used scientometrics to investigate the interdisciplinary changes in EER through co-authorship collaboration. ${ }^{15}$ Findings from this study revealed an increasingly high degree of disciplinarily diversity in EER related articles. 
Hidden structures within formal collaboration networks indicated by co-authorship can be described using social network analysis (SNA) methods. SNA's statistical metrics provide quantitative indicators of significant collaboration patterns within the network, such as centrality, information flow, critical individuals, and clique formation. ${ }^{16-18}$ Further, multiple studies have used SNA methods to analyze formal collaboration patterns visible through publication coauthorships. ${ }^{19-23}$ Researchers have agreed that co-authorship is a concrete and well documented, if not perfect, indicator of scientific collaboration. ${ }^{20,23-24}$ Within EER, a publically available computational program depicts network maps of co-authorship using bibliometric data. ${ }^{25}$ However, there have not been any studies analyzing the impact of an individual's access to EER resources to co-authorship.

The purpose of this paper is to answer the question "How is collaboration within the EER community of practice impacted by an individual's access to EER resources?" Formal collaborations were catalogued using co-authorship data from publications in the Journal of Engineering Education between the years 2008 to 2012. Influential researchers, collaboration trends, critical brokers, and other hidden structures were analyzed using social network analysis methods.

\section{Methodology}

\section{Data Collection}

The Journal of Engineering Education (JEE) is currently the premier journal of the EER community with over 11,000 readers. ${ }^{26} \mathrm{JEE}$ has an impact factor of 1.925 and articles within the journal have been cited 3,316 times. The 2012 impact factor places JEE fourth out of 38 journals in Education, Scientific disciplines, ninth out of 87 journals in Multidisciplinary Engineering, and sixteenth out of 219 journals in Education and Educational Research. ${ }^{27}$ Thus, this paper uses SNA to examine the interdisciplinary nature of JEE publications between the years 2008 to 2012 . The data was gathered by means of the Web of Science (WoS) database by Thomson Reuters using the search string "Publication Name=(Journal of Engineering Education) AND Year Published=(2008-2012)." Only full journal articles were included for analysis. The resulting 140 WoS articles were checked for consistency with the articles listed on JEE's website, and missing articles were added to the data set. The final compilation of citations was imported into VantagePoint, a text-mining software.

The listed authors and author affiliations were cleaned using an automatic filter in VantagePoint, and the resulting data set was manually verified. The final data set consisted of 152 articles written by 385 authors belonging to 128 organizations. Table 1 lists the mean, standard deviation, and range for number of publications by author and by organization (i.e. author affiliation). 
Table 1. Descriptive statistics for the number of articles per author

\begin{tabular}{ccc} 
Statistic & \# Articles per Author & \# Articles per Organization \\
\hline Mean & 1.27 & 2.12 \\
Standard Deviation & 0.817 & 3.72 \\
Minimum & 1 & 1 \\
Maximum & 10 & 37 \\
\hline
\end{tabular}

\section{Methodology}

SNA methods use network theory to examine social relationships. By using a network perspective, hidden structures of social relationships are exposed and used to enhance knowledge of social capital's flow and impact. ${ }^{4,28}$ On a network map the actors (i.e. population of interest) is represented by nodes. The relation (i.e. social exchange) between actors is represented by an edge connecting associated nodes. The network map for this study can be seen in the Results section of this paper.

A social network can be viewed at many levels. ${ }^{28}$ The lowest, simplest perspective is comprised of one actor (ego) and all other actors to which the ego has direct relations (alters). This egocentric perspective can be used to generalize close, personal networks of individual actors. At the highest level, the complete network uses every relation among all actors to give a macro analysis of the entire network's structure.

This publication uses a sample population to represent a macro view of collaboration within the complete EER network. Publication authors define the network actors, or nodes. Co-authorship associations define the relations between actors, or network edges. Additionally, an egocentric view highlights the close networks of engineering education researchers.

\section{Data Attributes}

The purpose of this paper is to answer the question "How is collaboration within the EER community of practice impacted by an individual's access to EER resources?" Thus, the availability of on-campus EER resources is classified using three categories: EER-academic department, on-campus EER center, or no on-campus EER resources. ${ }^{29}$

Table 2 lists the frequencies for organizations, authors, and publications by the availability of oncampus EER resources.

Table 2. Frequency of occurrence by the availability of on-campus EER resources (academic institutions only)

\begin{tabular}{cccc} 
Attribute & \# Organizations & \# Authors & \# Publications \\
\hline EER-Oriented Department & 5 & 68 & 51 \\
Eng/STEM Ed Research Center & 18 & 124 & 62 \\
No On-Campus Resources & 90 & 174 & 93 \\
\hline
\end{tabular}

Additionally, the type of organization each author was affiliated with is coded using five subcategories: university, international university, non-profit, government, industry. However, this publication does not discuss the general implications of the type of organization on co-authorship patterns. A full list of organizations is located in Appendix A. 


\section{Dependent Measures}

UCINet 6 was used to measure co-occurrences and interactions among author collaborations. ${ }^{30}$ Four metrics were identified to characterize the network: E-I Index, Degree Centrality, Betweeness Centrality, and Effective Size.

(External-Internal) E-I Index compares the number of ties inside a particular context (or attribute) to those outside that context. The EI Index is calculated as: (external ties - internal ties) / (external ties + internal ties) and ranges from negative one to one. A positive E-I Index indicates the grouping has a higher number of external ties than internal ties.

For this study, a positive E-I Index indicates that authors tend to collaborate with others not located at (i.e. external to) their home institution.

Degree Centrality measures an individual's relative importance within the network by describing how influential, or connected, that individual is to the entire network. This measure allows us to identify the presence and influence of 'critical individuals' in the network; those people who are key coordinators or actors.

For this study, a higher Degree Centrality indicates that an author is more influential to the coauthorship network and tends to be connected to many other co-authors.

Betweenness Centrality quantifies the number of times an individual acts as a bridge along the shortest path between two other nodes. This measure allows us to identify important "brokers" within the network, or individuals who have a unique capability to tie unconnected individuals in the network.

For this study, a higher Betweeness Centrality indicates that an author acts as a bridge between many other authors and is able to broker relationships between otherwise unconnected individuals.

Effective Size is used in egocentric networks to measure an actor's position in a network and is another indicator of important "brokers." As described earlier, The egocentric networks are comprised of one actor (ego) and all other actors to which the ego has direct relations (alters). The effective size of a network is found by taking the number of alters an ego has and subtracting the number of ties that each alter has to other alters or the number of alternate paths. A high effective size indicates that an individual is critical to bridging other nodes, particularly where no alternate connection exists between nodes.

For this study, a higher Effective Size indicates that an author acts as a bridge between many other authors and is able to broker relationships between otherwise unconnected individuals.

\section{Results}

Network maps were created using NetDraw. ${ }^{31}$ Authors (nodes) were coded by color for the availability of on-campus EER resources, and by shape for the type of organization (Table 3). The size of the node represents the number of publications that author published in JEE over the analyzed years, and the thickness of the edges (i.e. line) between nodes represents the number of co-authorships between two connected actors. Figure 1 depicts the network map for the complete network. 
Table 3. Node format and associated attribute

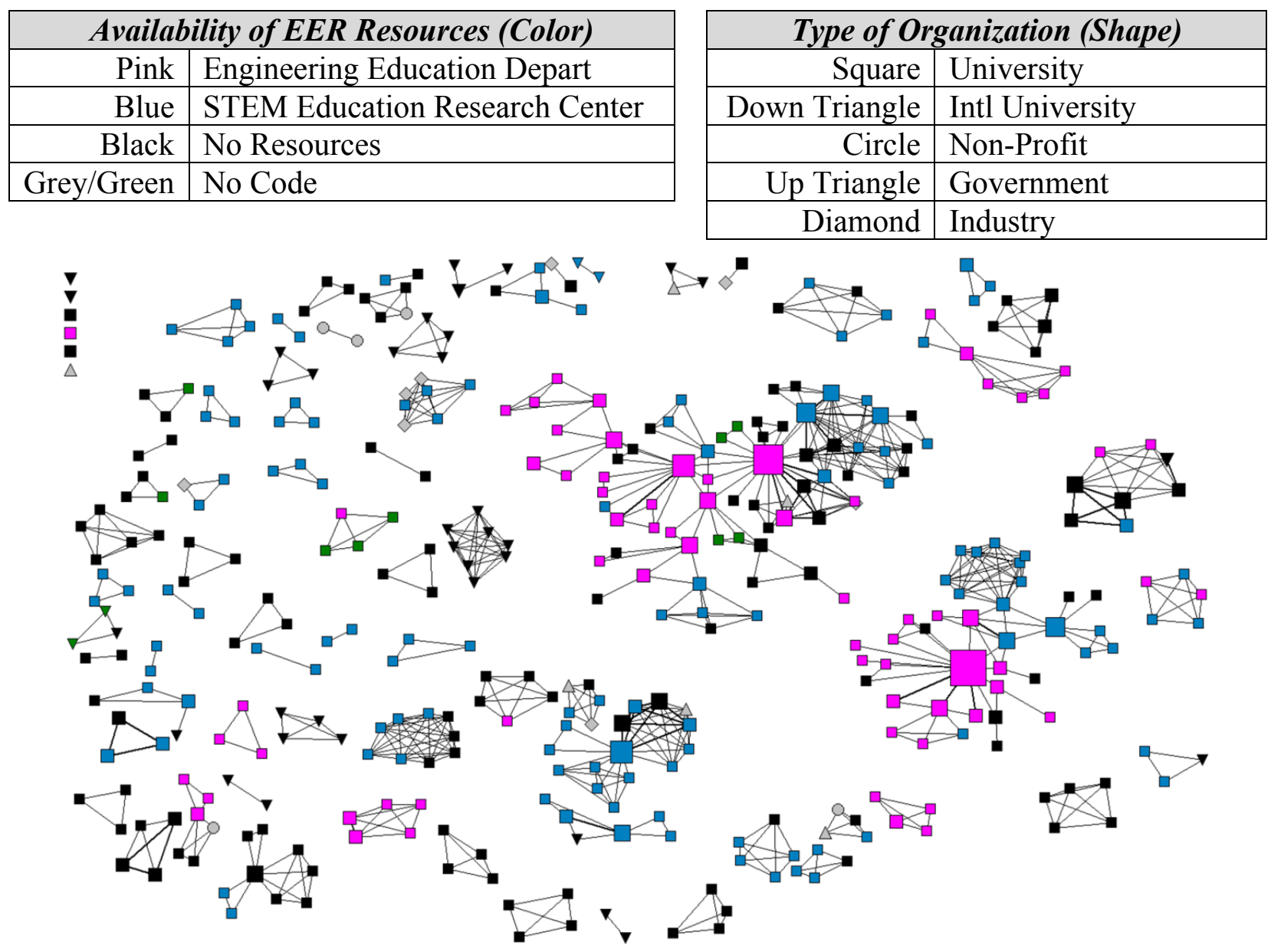

Figure 1. Network Map of Complete Network

\section{E-I Index}

The availability of engineering education resources is a significant factor to E-I Index, i.e. the number of publications coauthored with individuals located at the same university versus those publications featuring authors from multiple universities $(\mathrm{F}(2,91)=9.715$, $\mathrm{p}<0.001)$. Further, a Tukey Multiple Comparisons test shows that a difference in means exists between authors with an engineering education department and those who do not have an engineering education department (Figure 2). Authors affiliated with an engineering education department have a significantly lower E-I Index, however the

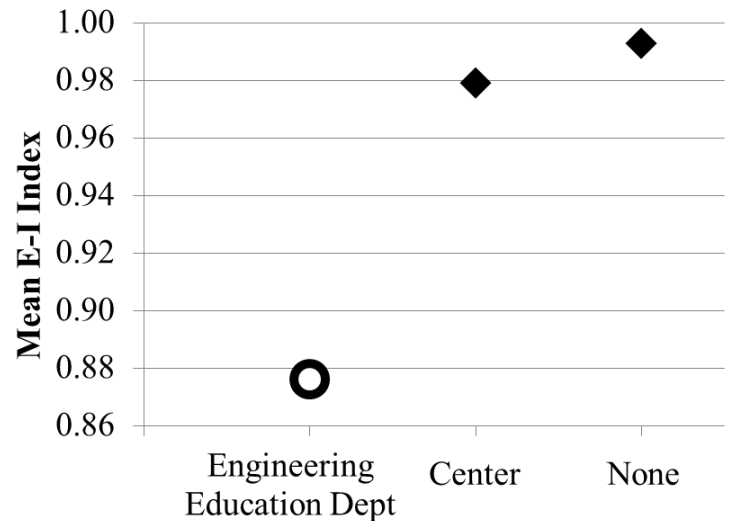

Figure 2. E-I Index by Availability of EER Resources positive index value reflects that most authors tend to collaborate outside their collocated network. 


\section{Centrality}

The availability of EER resources, was not a significant factor to Degree Centrality ( $F(2$, $363)=0.830, p>0.05$ ). However, ranking authors by their Degree Centrality demonstrates that highly ranked authors are primarily housed on campuses with access to either an engineering education department or a STEM education research center (Table 4)

Table 4. Authors with the top 10 Degree Centrality measures

\begin{tabular}{|c|c|c|c|c|}
\hline Author & University & $\begin{array}{c}\text { EER } \\
\text { Resources }\end{array}$ & $\begin{array}{c}\text { \# JEE } \\
\text { Articles }\end{array}$ & $\begin{array}{c}\text { Normalized } \\
\text { Degree } \\
\text { Centrality }\end{array}$ \\
\hline Ohland, Matthew W & Purdue University & Department & 8 & 2.517 \\
\hline Finelli, Cynthia J & University of Michigan & Center & 5 & 1.736 \\
\hline Sheppard, Sheri D & Stanford University & Center & 4 & 1.736 \\
\hline Borrego, Maura J & Virginia Tech & Department & 10 & 1.563 \\
\hline Chen, Helen L & Stanford University & Center & 3 & 1.215 \\
\hline Diefes-Dux, Heidi A & Purdue University & Department & 5 & 1.215 \\
\hline Long, Russell A & Purdue University & Department & 3 & 1.215 \\
\hline Carpenter, Donald D & Lawrence University & None & 3 & 1.128 \\
\hline Harding, Trevor S & Calif Polytech State Univ & None & 3 & 1.128 \\
\hline Lichtenstein, Gary & Stanford University & Center & 3 & 1.128 \\
\hline
\end{tabular}

An examination of Betweenness

Centrality shows that the availability of EER resources is a significant indicator $(\mathrm{F}(2,332)=11.204, \mathrm{p}<0.001)$. Further, a Tukey Multiple Comparisons test shows that a difference in means exists between authors affiliated with an engineering education department and those not affiliated with an engineering education department (Figure 3). Authors affiliated with an engineering education department have a larger Betweenness Centrality, indicating the presence of individuals who have a unique capability to broker relationships between unconnected individuals in the network.

A network map organized by university illustrates an interesting trend in network centrality (Figure 4). Authors without access to EER resources tend to be located toward the edge of the network map and have a more clustered relationship with few brokering individuals. Universities with engineering/STEM education research centers are further to the center of the circle, with a few individuals holding the ability to broker relationships between universities. Finally, the most central universities typically have an engineering education department. 


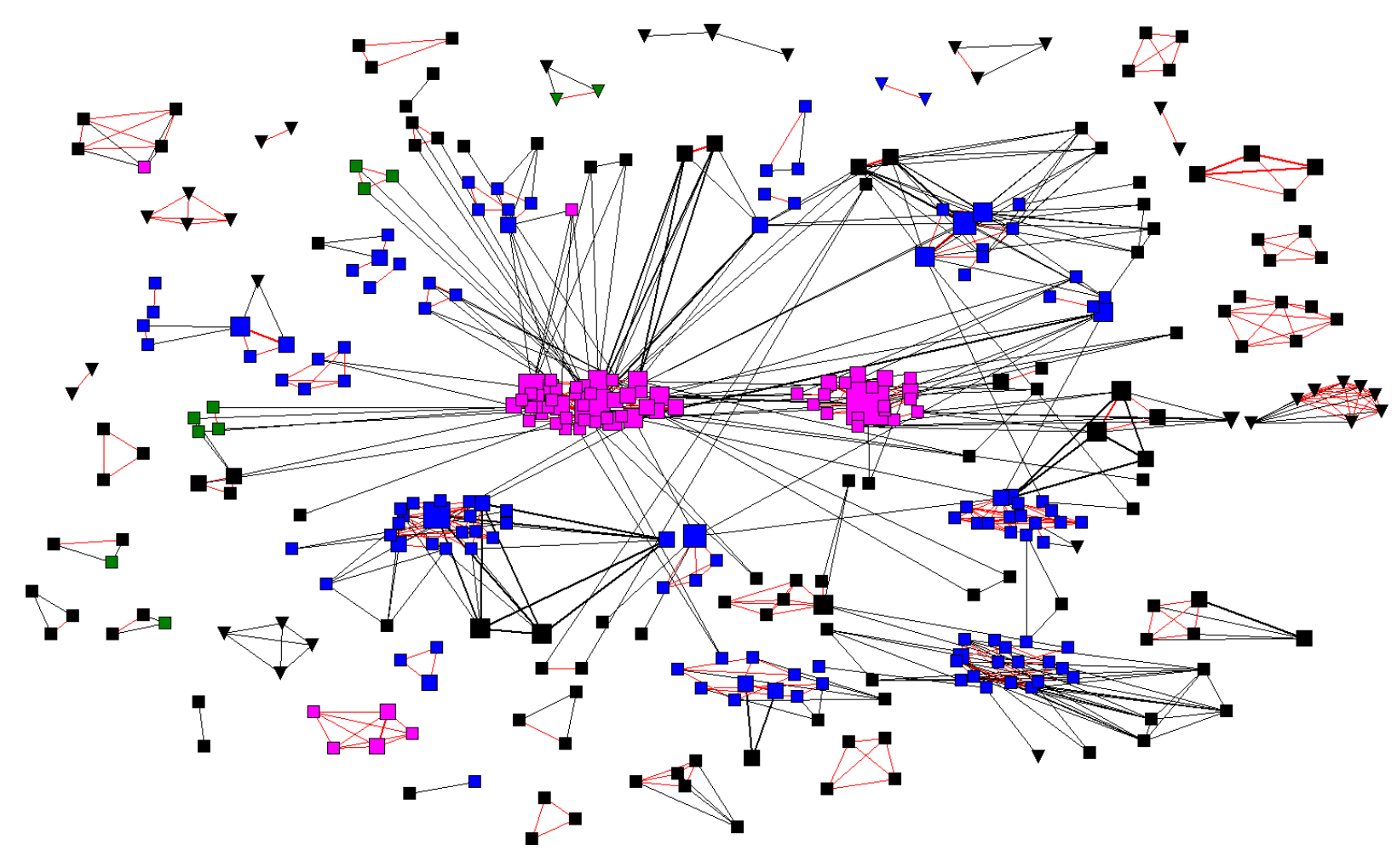

Figure 4. Network map, grouped by university (red lines indicate collaboration within university)

\section{Effective Size}

Examining the egocentric network, the availability of EER resources is significant to an ego's effective size $(\mathrm{F}(2,332)=8.53$, $\mathrm{p}<0.001)$. Further, a Tukey Multiple Comparisons test shows that a difference in means exists between those with an engineering education department and those who do not have an engineering education department. Figure 5 shows that individuals on campuses with engineering education departments have a greater mean Effective Size than those with only a research center or those with no resources, indicating the presence of individuals who have a unique capability to broker relationships between

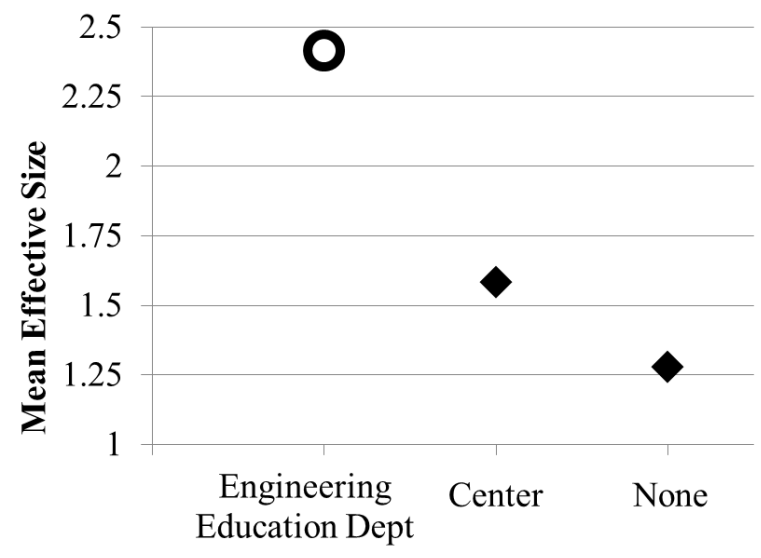

Figure 5. Effective Size by the availability of EER resources unconnected individuals in the network. 
Figure 6 depicts a visual comparison of ego networks grouped by availability of EER resources. The left image shows the ego network for those universities with engineering education departments and the right image shows the ego network those universities without engineering education departments. These maps illustrate that the universities with engineering education departments have several individuals who are important to brokering relationships and collaborations, while those on campuses without an engineering education department typically have a more clustered relationship with few critical individuals.

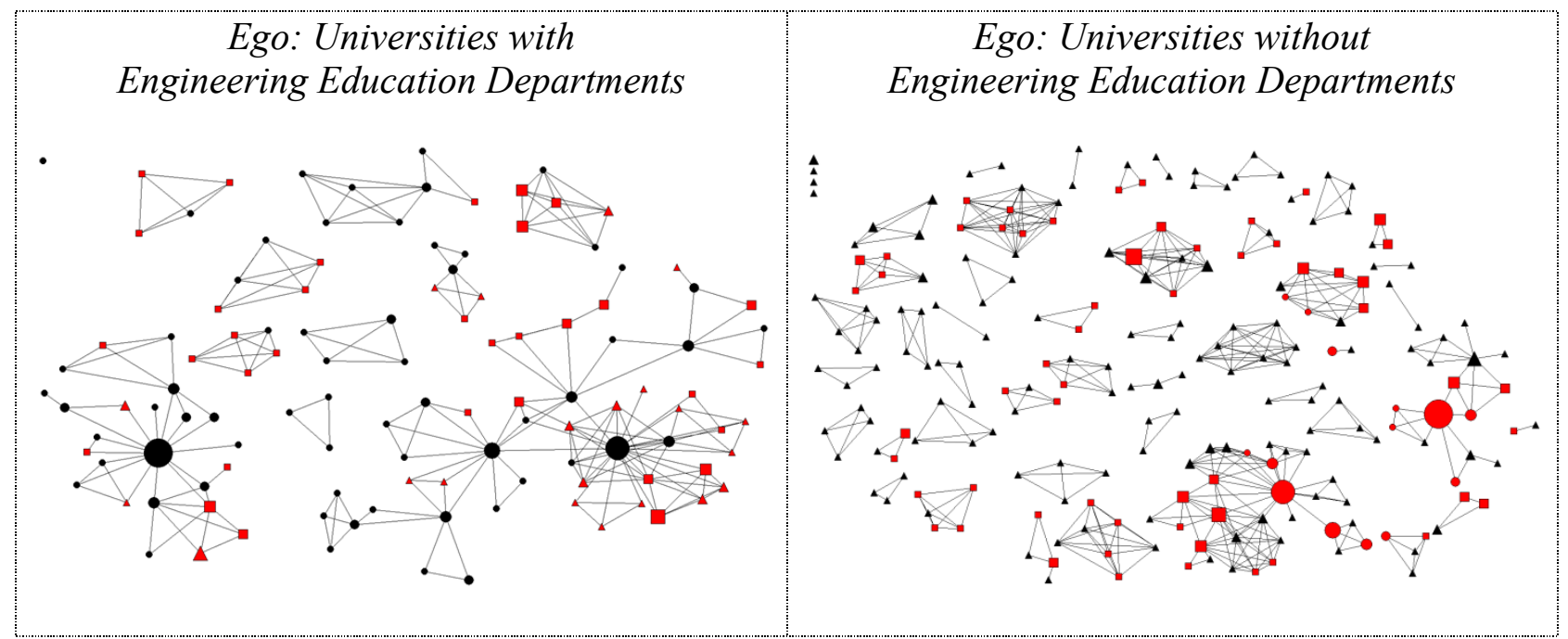

Figure 6. A visual comparison of ego-networks for differing levels of access to EER resources $($ ego $=$ black nodes, alters $=$ red nodes $)$

\section{Discussion and Conclusions}

The multidisciplinary distribution of EER expertise enables and encourages collaboration between engineering education researchers from a variety of backgrounds. While many of these researchers' perceptions of how to improve engineering education stem from traditional classroom experiences, a select group of researchers belong to departments, labs, and centers primarily devoted to studying EER. Institutions with an engineering education department typically have a high research production and greater impact within the field of EER. While only $5 \%$ of the analyzed academic organizations have an engineering education department, those same institutions comprised $19 \%$ of the authors and $25 \%$ of the publications found in JEE from 2008-2012. The fifty-one JEE articles published by individuals affiliated with engineering education departments have been collectively cited 291 times, or approximately 5.7 citations per paper. Authors not affiliated with an engineering education department are cited at a lower rate with only 4.7 citations per paper.

Authors affiliated with an engineering education department are typically central and influential collaborators within EER. However, results of this study found that researchers on campuses lacking formal EER resources may not have adequate access to this "expert" network and lack the ability to broker connections into EER's expert community of practice. Consequently, these researchers may be unable to adopt best practices from and exchange relevant information with the greater community. 
Researchers not affiliated with an engineering education department may have difficulty accessing EER's expert network due to the limited number of researchers belonging to engineering education departments. Thus, the EER community must create opportunities for researchers without access to formal EER resources to collaborate with other researchers. One potential solution may be to look at the current engineering education multi-day workshops/symposiums, such as the National Effective Teaching Institute, How to Engineer Engineering Education, and Making Academic Change Happen, and create a similar event that will compliment these by serving as an open forum for collaboration. The intent of the multi-day event would be to create an open forum for the discussion and exchange of ideas between innovative instructors and engineering education researchers. The symposium would act as a bridge and connect instructors actively reshaping courses at their home institution with prominent EER practitioners. The instructors would be encouraged to collaborate with engineering education researchers to improve their course design as well as formally examine and disseminate information about the impact of the implemented changes.

While the discussed research focuses on formal collaborations typified by JEE articles, informal collaborations and mentorship networks were not included in the analysis. Thus, a future study will use surveys to examine informal collaboration and mentorship networks in EER. Results from this future study will assist the engineering education community in creating effective programs for supporting unconnected researchers, particularly researchers independently performing engineering education research within their specific discipline.

\section{Acknowledgements}

This work is supported by the National Science Foundation Graduate Research Fellowship under Grant No. DGE-0644493. The author would like to acknowledge and thank Dr. Julia Melkers for her guidance on SNA literature and methods. Additionally, thank you to Alexandra Coso for her assistance in navigating the engineering education researcher community and EER literature.

\section{References}

1. Peterson, B.J. (1993). The costs and benefits of collaborative research. Estuaries, 16(4), 913-918.

2. Katz, J.S. and Martin, B.R. (1997). What is research collaboration? Research Policy, 26(1), 1-18.

3. Sooho, L. and Bozeman, B. (2005). The impact of research collaboration on scientific productivity. Social Studies of Science (Sage Publications, Ltd.), 35(5), 673-702.

4. Lin, N. (2001). Building a network theory of social capital. In R.S. Burt, K. Cook, N. Lin (Eds.), Social capital: Theory and research (pp. 3-29). New Brunswish, NJ: Transaction Publishers

5. (2005). Facilitating interdisciplinary research / Committee on Facilitating Interdisciplinary Research, Committee on Science, Engineering, and Public Policy, National Academy of Sciences, National Academy of Engineering, and Institute of Medicine. Washington, D.C. : National Academies Press.

6. McPherson, J.M., Smith-Lovin, L., and Cook, J.M. (2001). Birds of a feather: Homophily in social networks. Annual Review of Sociology, 27(1), 415-444.

7. Borrego, M.J., and Newswander, L.K. (2008). Characteristics of successful cross-disciplinary engineering 
education collaborations. Journal of Engineering Education, 97(2), 123-134.

8. Borrego, M.J., and Bernhard, J. (2011). The emergence of engineering education research as an internationally connected field of inquiry. Journal of Engineering Education, 100(1), 14-47.

9. Borrego, M.J. (2007). Development of engineering education as a rigorous discipline: A Study of the Publication Patterns of Four Coalitions. Journal of Engineering Education, 96(1), 5-18.

10. Jesiek, B.K., Newswander, L.K., and Borrego, M.J. (2009). Engineering education research: discipline, community, or field? Journal of Engineering Education, 98(1), 39-52.

11. Burt, R.S. (2004). Structural holes and good ideas. American Journal of Sociology, 110(2), 349-400.

12. Coso, A., Louis, R., London, J., Ngambeki, I., and Sattler, B. (2012). Exploring the reasons for collaboration and cooperation among graduate student researchers. Paper presented at the ASEE Conference, San Antonio, TX.

13. Olds, B.M. Moskal, B.M. and Miller, R.L. (2005). Assessment in engineering education: Evolution, approaches and future collaborations. Journal of Engineering Education, 94(1), 13-25.

14. Mckenna, A.F. Yalvac, B. and Light. G.J. (2009). The role of collaborative reflection on shaping engineering faculty teaching approaches. Journal of Engineering Education, 98(1), 17-26.

15. Strobel, J, Radcliffe, D.F., Yu, J.H., Nawaz, S., Luo, Y., and Choi, J.H. (2012). Is the Engineering Education community becoming more interdisciplinary? Paper presented at the ASEE Conference, San Antonio, TX.

16. Wasserman, S., and Faust. K. (1994). Social network analysis: methods and applications. Cambridge, New York: Cambridge University Press.

17. Kadushin, C. (2012). Understanding social networks: concepts, theories, and findings. New York: Oxford University Press.

18. Borgatti, S.P., Everett, M.G., and Johnson, J.C. (2013). Analyzing social networks. Thousand Oaks, California: SAGE Publications.

19. Obermeier, U., and Brauckmann, H. (2010). Interdisciplinary patterns of a university: Investigating collaboration using co-publication network analysis. COLLNET Journal of Scientometrics and Information Management, 4(1). 29-40.

20. Velden, T., Haque, A.U., and Lagoze C. (2010). A new approach to analyzing patterns of collaboration in co-authorship networks: Mesoscopic analysis and interpretation. Scientometrics, 85(1), 219-242.

21. Birnholtz, J., Guha, S., Gay, G., Yuan, Y., and Heller C. (2013). Cross-campus collaboration: A scientometric and network case study of publication activity across two campuses of a single institution. Journal of the American Society for Information Science and Technology, 64(1), 162-172.

22. Chen, Y.W., Borner, K., and Fang, S. (2013). Evolving collaboration networks in Scientometrics in 19782010: A micro-macro analysis. Scientometrics, 95(3), 1051-1070.

23. Glanzel, W., and Schubert A. (2004). Analysing scientific networks through co-authorship. In H.F. Moed, W. Glanzel, U. Schmoch (Eds.) Handbook of quantitative science and technology research: The use of publication and patent statistics in studies of S\&T systems (pp. 257-276). Boston and London: Dordrecht.

24. Smith, M. (1958). The trend toward multiple authorship in psychology. American Psychologist 13(10), 596-599.

25. Madhavan, K., Xian, H., Vorvoreanu, M., Jesiek, B., Johri, A., Wang, A., and Wankat, P. (2010) Interactive Knowledge Networks for Engineering Education Research (iKNEER). Supported by NSF Grant EEC-0957015, EEC-0935109, EEC-0935124.

26. Lohmann, J.R. (2010). JEE strategic plan, 2005-2010: A summary report. Journal of Engineering Education, 99(4): 279-283.

27. "Journal of Engineering Education." Journal of Engineering Education. Wiley Online Library, http://onlinelibrary.wiley.com/journal/10.1002/(ISSN)2168-9830, Accessed 1 Dec. 2013

28. Knoke, D., and Yang S. (2008). Social Network Analysis. Thousand Oaks, California: SAGE Publications, Inc. 
29. Carberry, A., and Yasuhara, K. "Engineering Education Community Resource." $\mathrm{http} / /$ engineeringeducationlist.pbworks.com/w/page/27578912/Engineering\%20Education\%20Community \%20Resource, Accessed 1 Dec. 2013.

30. Borgatti, S.P., Everett, M.G., and Freeman, L.C. (2002). UCINet for Windows: Software for Social Network Analysis. Harvard, MA: Analytic Technologies.

31. Borgatti, S.P. (2002). NetDraw: Graph Visualization Software. Harvard: Analytic Technologies. 


\section{Appendix: Organization Attributes}

\begin{tabular}{|l|l|}
\hline \multicolumn{2}{|c|}{ Availability of EER Resources } \\
\hline 1 & Engineering Education Department \\
\hline 2 & Engineering or STEM Education Research Center \\
\hline 3 & No On-Campus Resources \\
\hline
\end{tabular}

\begin{tabular}{|c|l|}
\hline \multicolumn{2}{|c|}{ Basic Carnegie Classification } \\
\hline RU/VH & Research Universities (very high research activity) \\
\hline RU/H & Research Universities (high research activity) \\
\hline Bac/A\&S & Baccalaureate Colleges--Arts \& Sciences \\
\hline Master's L & Master's Colleges and Universities (larger programs) \\
\hline DRU & Doctoral/Research Universities \\
\hline Spec/Eng & Special Focus Institutions--Schools of engineering \\
\hline Bac/Diverse & Baccalaureate Colleges--Diverse Fields \\
\hline Master's M & Master's Colleges and Universities (medium programs) \\
\hline
\end{tabular}

Carnegie Eng Ed Num Num

\begin{tabular}{|c|c|c|c|c|c|}
\hline Organization & Org Type & Classification & Resources & Records & Authors \\
\hline Aalto University & Intl Univ & & 3 & 1 & 1 \\
\hline $\begin{array}{l}\text { American Association for the } \\
\text { Advancement of Science }\end{array}$ & Non-Profit & & & 1 & 1 \\
\hline $\begin{array}{l}\text { American Institutes for } \\
\text { Research }\end{array}$ & Non-Profit & & & 1 & 1 \\
\hline Arizona State University & University & RU/VH & 2 & 6 & 11 \\
\hline $\begin{array}{l}\text { Association of State \& } \\
\text { Territorial Health Officials }\end{array}$ & Non-Profit & & & 1 & 1 \\
\hline Beijing University & & & 3 & & \\
\hline Aeronautics \& Astronautics & Intl Univ & & & 1 & 1 \\
\hline Boeing & Industry & & & 1 & 3 \\
\hline Boston College & University & $\mathrm{RU} / \mathrm{H}$ & 3 & 1 & 2 \\
\hline Brigham Young University & University & $\mathrm{RU} / \mathrm{H}$ & 2 & 1 & 1 \\
\hline Bucknell University & University & $\mathrm{Bac} / \mathrm{A} \& \mathrm{~S}$ & 3 & 1 & 3 \\
\hline $\begin{array}{l}\text { California Polytech State } \\
\text { University San Luis Obispo }\end{array}$ & University & Master's L & 3 & 5 & 4 \\
\hline California State University- & & & 3 & & \\
\hline Fullerton & University & Master's L & & 2 & 1 \\
\hline $\begin{array}{l}\text { Carnegie Foundation for the } \\
\text { Advancement of Teaching }\end{array}$ & Non-Profit & & & 1 & 2 \\
\hline Carnegie Mellon University & University & RU/VH & 2 & 6 & 5 \\
\hline Central Queensland & & & 3 & & \\
\hline University & Intl Univ & & & 1 & 1 \\
\hline City University Hong Kong & Intl Univ & & 3 & 1 & 1 \\
\hline Clarkson University & University & $\mathrm{RU} / \mathrm{H}$ & 3 & 1 & 4 \\
\hline
\end{tabular}




\begin{tabular}{|c|c|c|c|c|c|}
\hline Organization & Org Type & $\begin{array}{c}\text { Carnegie } \\
\text { Classification }\end{array}$ & $\begin{array}{l}\text { Eng Ed } \\
\text { Resources }\end{array}$ & $\begin{array}{l}\text { Num } \\
\text { Records }\end{array}$ & $\begin{array}{c}\text { Num } \\
\text { Authors }\end{array}$ \\
\hline Clemson University & University & $\mathrm{RU} / \mathrm{H}$ & 1 & 1 & 1 \\
\hline Colorado School of Mines & University & RU/H & 2 & 7 & 5 \\
\hline Colorado State University & University & RU/VH & 3 & 1 & 2 \\
\hline CUNY City College & University & Master's L & 3 & 2 & 2 \\
\hline Curtin University Australia & Intl Univ & & 3 & 1 & 1 \\
\hline Dartmouth College & University & RU/VH & 3 & 1 & 1 \\
\hline Duke University & University & $\mathrm{RU} / \mathrm{VH}$ & 3 & 1 & 4 \\
\hline East Carolina University & University & DRU & 3 & 1 & 1 \\
\hline Education Designs Inc & Industry & & & 1 & 1 \\
\hline Education Northwest & Industry & & & 1 & 1 \\
\hline Fairleigh Dickinson Univ & University & Master's L & 3 & 1 & 1 \\
\hline Florida State University & University & RU/VH & 3 & 1 & 4 \\
\hline $\begin{array}{l}\text { Franklin W. Olin College of } \\
\text { Engineering }\end{array}$ & University & Snec/Engo & 3 & 3 & 3 \\
\hline George Mason University & University & $\mathrm{RU} / \mathrm{H}$ & 3 & 1 & 1 \\
\hline George Washington & & & 3 & & \\
\hline University & University & RU/VH & & 1 & 3 \\
\hline Georgia Institute of & & & 3 & & \\
\hline Technology-Main Campus & University & RU/VH & & 2 & 7 \\
\hline Harvard University & University & $\mathrm{RU} / \mathrm{VH}$ & 3 & 1 & 1 \\
\hline Hewlett Packard Corp & Industry & & & 1 & 1 \\
\hline Howard University & University & $\mathrm{RU} / \mathrm{H}$ & 3 & 1 & 1 \\
\hline Illinois Institute of & & & 3 & & \\
\hline Technology & University & $\mathrm{RU} / \mathrm{H}$ & & 1 & 1 \\
\hline Indiana University-Main & & & 3 & & \\
\hline Campus & University & DRU & & 1 & 1 \\
\hline Indiana University-Purdue & & & 3 & & \\
\hline University-Fort Wayne & University & Master's L & & 1 & 1 \\
\hline Iowa State University & University & RU/VH & 3 & 1 & 1 \\
\hline $\begin{array}{l}\text { Korea Fdn for the Adv of } \\
\text { Science \& Creativity }\end{array}$ & Intl Gov & & & 1 & 1 \\
\hline Lawrence University & University & $\mathrm{Bac} / \mathrm{A} \& \mathrm{~S}$ & 3 & 3 & 1 \\
\hline Linkoping University & Intl Univ & & 3 & 1 & 2 \\
\hline Loughborough University & Intl Univ & & 2 & 1 & 2 \\
\hline Marshall University & University & Master's L & 3 & 1 & 1 \\
\hline Massachusetts Institute of & & & 2 & & \\
\hline Technology & University & $\mathrm{RU} / \mathrm{VH}$ & & 1 & 1 \\
\hline Miami University-Oxford & University & $\mathrm{RU} / \mathrm{H}$ & 3 & 1 & 1 \\
\hline Michigan State University & University & $\mathrm{RU} / \mathrm{VH}$ & 2 & 1 & 1 \\
\hline $\begin{array}{l}\text { Ministry of Educ, Culture, } \\
\text { Sports, Science \& Tech }\end{array}$ & Intl Gov & & & 1 & 1 \\
\hline Minnesota State University- & & & 3 & & \\
\hline Mankato & University & Master's L & & 1 & 1 \\
\hline Nanyang Tech University & Intl Univ & & 3 & 2 & 2 \\
\hline $\begin{array}{l}\text { National Academy of } \\
\text { Engineering }\end{array}$ & Government & & & 1 & 1 \\
\hline $\begin{array}{l}\text { National Pingtung University } \\
\text { of Science \& Technology }\end{array}$ & Intl Univ & & 3 & 2 & 1 \\
\hline National Science Foundation & Government & & & 1 & 2 \\
\hline
\end{tabular}




\begin{tabular}{|c|c|c|c|c|c|}
\hline Organization & Org Type & $\begin{array}{c}\text { Carnegie } \\
\text { Classification }\end{array}$ & $\begin{array}{l}\text { Eng Ed } \\
\text { Resources }\end{array}$ & $\begin{array}{l}\text { Num } \\
\text { Records }\end{array}$ & $\begin{array}{l}\text { Num } \\
\text { Authors }\end{array}$ \\
\hline $\begin{array}{l}\text { National Taiwan University } \\
\text { of Science \& Tech }\end{array}$ & Intl Univ & & 3 & (2) & 2 \\
\hline $\begin{array}{l}\text { Natural Sciences \& Eng } \\
\text { Research Council }\end{array}$ & Government & & & 1 & 1 \\
\hline North Carolina State & & & 3 & & \\
\hline University at Raleigh & University & RU/VH & & 1 & 1 \\
\hline Northeastern University & University & RU/H & 3 & 1 & 4 \\
\hline Northwestern University & University & RU/VH & 3 & 4 & 8 \\
\hline Ohio State University & & & 1 & & \\
\hline Main Campus & University & RU/VH & & 2 & 5 \\
\hline Oklahoma Baptist University & University & Bac/Diverse & 3 & 1 & 1 \\
\hline Oklahoma State University & & & 3 & & \\
\hline Main Campus & University & $\mathrm{RU} / \mathrm{H}$ & & 1 & 1 \\
\hline Old Dominion University & University & $\mathrm{RU} / \mathrm{H}$ & 3 & 1 & 1 \\
\hline Oregon State University & University & $\mathrm{RU} / \mathrm{VH}$ & 2 & 2 & 4 \\
\hline Pennsylvania State & & & 2 & & \\
\hline University-Main Campus & University & RU/VH & & 8 & 17 \\
\hline Pepperdine University & University & DRU & 3 & 1 & 1 \\
\hline Purdue University & & & 1 & & \\
\hline Main Campus & University & RU/VH & & 37 & 42 \\
\hline $\begin{array}{l}\text { Research Triangle } \\
\text { Educational Consultants }\end{array}$ & Industry & & & 2 & 1 \\
\hline Rose-Hulman Institute of & & & 2 & & \\
\hline Technology & University & Spec/Engg & & 4 & 4 \\
\hline Rowan University & University & Master's L & 3 & 1 & 2 \\
\hline Saint Louis University & & & 3 & & \\
\hline Main Campus & University & $\mathrm{RU} / \mathrm{H}$ & & 1 & 1 \\
\hline Seattle Pacific University & University & Master's L & 3 & 1 & 1 \\
\hline Shanghai University & Intl Univ & & 3 & 1 & 1 \\
\hline Simmons College & University & Master's L & 3 & 1 & 1 \\
\hline Stanford University & University & RU/VH & 2 & 7 & 9 \\
\hline Suffolk University & University & Master's L & 3 & 1 & 1 \\
\hline $\begin{array}{l}\text { Technion - Israel Institute of } \\
\text { Technology }\end{array}$ & Intl Univ & & 3 & 1 & 1 \\
\hline Temasek Polytech & Intl Univ & & 3 & 1 & 7 \\
\hline Texas A\&M University & University & $\mathrm{RU} / \mathrm{VH}$ & 3 & 2 & 2 \\
\hline Texas Tech University & University & $\mathrm{RU} / \mathrm{H}$ & 2 & 2 & 3 \\
\hline The University of Alabama & University & $\mathrm{RU} / \mathrm{H}$ & 3 & 1 & 1 \\
\hline The University of Tennessee & & & 3 & & \\
\hline Martin & University & Master's M & & 1 & 1 \\
\hline $\begin{array}{l}\text { The University of Texas at } \\
\text { Austin }\end{array}$ & University & RU/VH & 3 & 1 & 1 \\
\hline The University of Texas & & & 3 & & \\
\hline Pan American & University & Master's L & & 1 & 1 \\
\hline Tufts University & University & RU/VH & 3 & 2 & 4 \\
\hline Tuskegee University & University & Bac/Diverse & 3 & 1 & 1 \\
\hline United States Military & & & 3 & & \\
\hline Academy & University & $\mathrm{Bac} / \mathrm{A} \& \mathrm{~S}$ & & 1 & 1 \\
\hline Universidad de La Laguna & Intl Univ & & 3 & 1 & 2 \\
\hline
\end{tabular}




\begin{tabular}{|c|c|c|c|c|c|}
\hline Organization & Org Type & $\begin{array}{c}\text { Carnegie } \\
\text { Classification }\end{array}$ & $\begin{array}{l}\text { Eng Ed } \\
\text { Resources }\end{array}$ & $\begin{array}{c}\text { Num } \\
\text { Records }\end{array}$ & $\begin{array}{c}\text { Num } \\
\text { Authors }\end{array}$ \\
\hline Universidad de La Rioja & Intl Univ & & 3 & 1 & 4 \\
\hline Universidad Politécnica de & & & 3 & & \\
\hline Valencia & Intl Univ & & & 1 & 1 \\
\hline University of Alberta & Intl Univ & & 3 & 1 & 1 \\
\hline University of Auckland & Intl Univ & & 3 & 1 & 1 \\
\hline University of Colorado at & & & 3 & & \\
\hline Boulder & University & RU/VH & & 2 & 2 \\
\hline University of Connecticut & University & RU/VH & 3 & 2 & 4 \\
\hline University of Florida & University & RU/VH & 3 & 3 & 3 \\
\hline University of Georgia & University & RU/VH & 3 & 1 & 3 \\
\hline University of Houston & University & RU/VH & 3 & 1 & 4 \\
\hline University of Louisville & University & RU/VH & 3 & 1 & 1 \\
\hline University of Manitoba & Intl Univ & & 3 & 1 & 2 \\
\hline $\begin{array}{l}\text { University of Maryland- } \\
\text { College Park }\end{array}$ & University & RU/VH & 3 & 1 & 1 \\
\hline University of Massachusetts & & & 3 & & \\
\hline Amherst & University & RU/VH & & 1 & 2 \\
\hline University of Melbourne, & & & 3 & & \\
\hline Australia & Intl Univ & & & 1 & 1 \\
\hline University of Michigan & & & 2 & & \\
\hline Ann Arbor & University & RU/VH & & 9 & 19 \\
\hline University of Missouri & & & 3 & & \\
\hline Columbia & University & $\mathrm{RU} / \mathrm{VH}$ & & 4 & 3 \\
\hline University of Nebraska & & & 3 & & \\
\hline Lincoln & University & RU/VH & & 1 & 2 \\
\hline University of Nevada-Reno & University & RU/H & 3 & 1 & 1 \\
\hline University of New Hampshire & & & 2 & & \\
\hline Main Campus & University & $\mathrm{RU} / \mathrm{H}$ & & 1 & 2 \\
\hline University of New Mexico & & & 3 & & \\
\hline Main Campus & University & RU/VH & & 2 & 1 \\
\hline University of Notre Dame & University & RU/VH & 3 & 1 & 3 \\
\hline University of Oklahoma & & & 2 & & \\
\hline Norman Campus & University & $\mathrm{RU} / \mathrm{VH}$ & & 4 & 8 \\
\hline University of Pittsburgh & University & $\mathrm{RU} / \mathrm{VH}$ & 2 & 3 & 6 \\
\hline University of Pretoria & Intl Univ & & 3 & 1 & 1 \\
\hline University of Rochester & University & RU/VH & 3 & 1 & 1 \\
\hline University of San Diego & University & DRU & 3 & 2 & 2 \\
\hline University of South Dakota & University & $\mathrm{RU} / \mathrm{H}$ & 3 & 1 & 1 \\
\hline University of South Florida- & & & 3 & & \\
\hline Tampa & University & $\mathrm{RU} / \mathrm{VH}$ & & 2 & 2 \\
\hline University of Sydney & Intl Univ & & 3 & 1 & 2 \\
\hline University of Vermont & University & $\mathrm{RU} / \mathrm{H}$ & 3 & 1 & 3 \\
\hline University of Washington & & & 2 & & \\
\hline Seattle Campus & University & RU/VH & & 8 & 18 \\
\hline University of Wisconsin & & & 3 & & \\
\hline Madison & University & $\mathrm{RU} / \mathrm{VH}$ & & 3 & 5 \\
\hline Urban Institute & Industry & & & 1 & 1 \\
\hline Utah State University & University & RU/H & 1 & 1 & 1 \\
\hline Vanderbilt University & University & $\mathrm{RU} / \mathrm{VH}$ & 3 & 3 & 3 \\
\hline
\end{tabular}




\begin{tabular}{|c|c|c|c|c|c|}
\hline Organization & Org Type & $\begin{array}{c}\text { Carnegie } \\
\text { Classification }\end{array}$ & $\begin{array}{c}\text { Eng Ed } \\
\text { Resources }\end{array}$ & $\begin{array}{c}\text { Num } \\
\text { Records }\end{array}$ & $\begin{array}{c}\text { Num } \\
\text { Authors }\end{array}$ \\
\hline Virginia Commonwealth & & & 3 & & \\
\hline University & University & RU/VH & & 1 & 1 \\
\hline Virginia Polytechnic Institute & & & 1 & & \\
\hline \& State University & University & RU/VH & & 16 & 19 \\
\hline Washington State University & University & RU/VH & 2 & 5 & 8 \\
\hline Western Washington & & & 3 & & \\
\hline University & University & Master's L & & 1 & 1 \\
\hline Xi'an University of & & & 3 & & \\
\hline Architecture \& Tech & Intl Univ & & & 1 & 1 \\
\hline
\end{tabular}

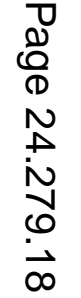

